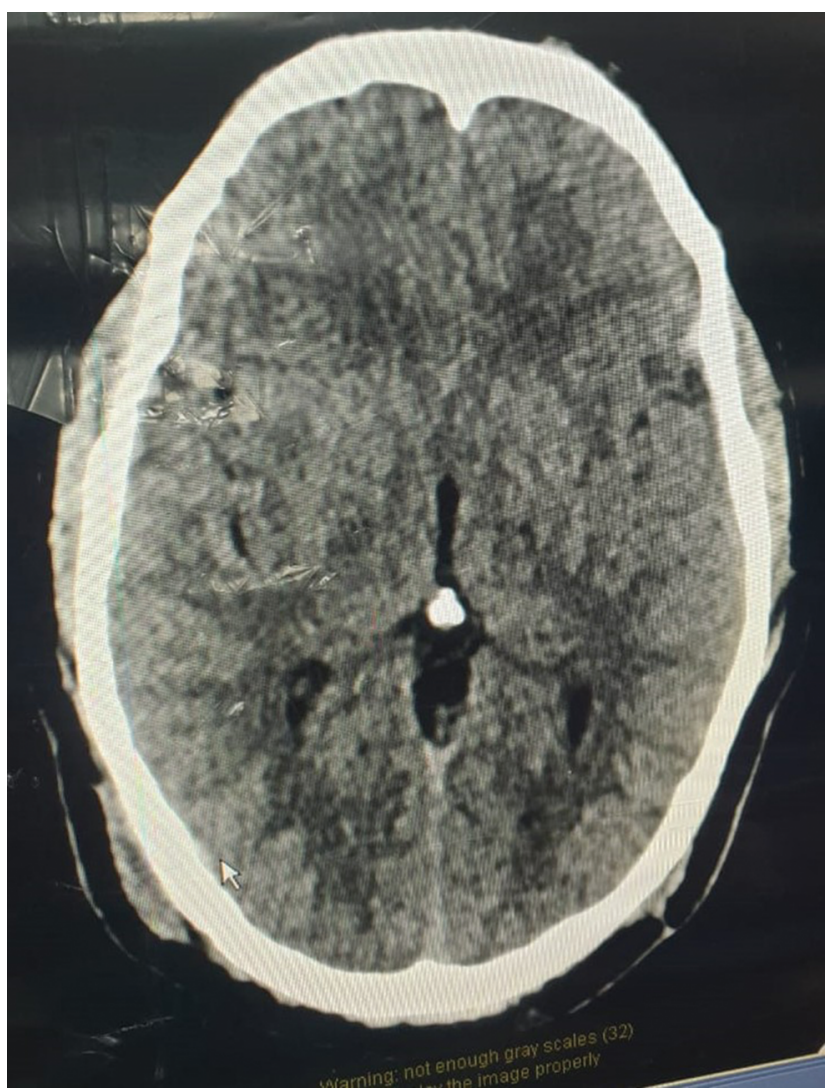

Fig. 1 Computed tomography scan of the patient, showing right occipital bone fracture with a small extradural hematoma (EDH).

General anesthesia, besides interfering with neurological examination, can result in intubation response, intraoperative hypotension/hypertension, hypoxia, and hypo/hypercarbia, which can be deleterious for intracranial and cerebral perfusion pressure. Conscious sedation with peripheral nerve block is optimal in cooperative patients. As the patient was fully conscious and cooperative, we planned for ultrasound-guided peripheral nerve block and dexmedetomidine sedation. Such a technique has several advantages like abolition of surgical stress, minimal interference with hemodynamics, and awake patient, allowing for neurological examination. Dexmedetomidine causes minimal interference with cerebral oxygenation in patients with TBI. ${ }^{2}$ Ultrasound has revolutionized peripheral nerve blocks which can be given with more certainty and effectivity while avoiding neural trauma and high drug dosage. ${ }^{3}$

Our case described feasibility of surgery under peripheral nerve blocks with conscious sedation in patients with recent head injury. Peripheral nerve block with dexmedetomidine infusion provided excellent operating conditions and ensured good systemic and cerebral hemodynamics, and conscious sedation allowed simultaneous neurological monitoring.

\section{Funding}

None.

\section{Conflict of Interest}

None declared.

\section{References}

1 Carney N, Totten AM, O'Reilly C, et al. Guidelines for the management of severe traumatic brain injury. 4 th ed. Neurosurgery 2017;80(1):6-15

2 Wang X, Ji J, Fen L, Wang A. Effects of dexmedetomidine on cerebral blood flow in critically ill patients with or without traumatic brain injury: a prospective controlled trial. Brain Inj 2013;27(13-14):1617-1622

3 Koscielniak-Nielsen ZJ. Ultrasound-guided peripheral nerve blocks: what are the benefits? Acta Anaesthesiol Scand 2008;52(6):727-737

\title{
A Diagnostic Dilemma in Combined Central Diabetes Insipidus and Cerebral Salt Wasting Syndrome
}

\author{
Jayanth Seshan ${ }^{1}$ Hirok Roy ${ }^{1}$ Charu Mahajan ${ }^{1}$ Indu Kapoor ${ }^{1}$ Hemanshu Prabhakar
}

\author{
${ }^{1}$ Department of Neuroanaesthesiology and Critical Care, All India \\ Institute of Medical Sciences, New Delhi, India
}

J Neuroanaesthesiol Crit Care 2021;8:153-154.

Published online June 1, 2020
DOI https://doi.org/ 10.1055/s-0040-1712068 ISSN 2348-0548.
Address for correspondence Charu Mahajan, MD, DM, Department of Neuroanaesthesiology and Critical Care, Neurosciences Centre, All India Institute of Medical Sciences, New Delhi 110029, India (e-mail: charushrikul@gmail.com).

(c) 2020. Indian Society of Neuroanaesthesiology and Critical Care. This is an open access article published by Thieme under the terms of the Creative Commons Attribution-NonDerivative-NonCommercial-License, permitting copying and reproduction so long as the original work is given appropriate credit. Contents may not be used for commercial purposes, or adapted, remixed, transformed or built upon. (https://creativecommons.org/licenses/by-nc-nd/4.0/).

Thieme Medical and Scientific Publishers Pvt. Ltd. A-12, 2nd Floor, Sector 2, Noida-201301 UP, India 
Table 1 Trend of different values

\begin{tabular}{|c|c|c|c|c|c|c|c|}
\hline Day & $\begin{array}{l}\text { Serum sodium } \\
(\mathrm{mEq} / \mathrm{L})\end{array}$ & $\begin{array}{l}\text { Urine } \\
\text { osmolality } \\
\text { (mOsm } / \mathrm{kg})\end{array}$ & $\begin{array}{l}\text { Serum } \\
\text { osmolality } \\
(\mathrm{mOsm} / \mathrm{kg})\end{array}$ & \begin{tabular}{|l} 
Urine spot \\
sodium \\
(mEq/L)
\end{tabular} & $\begin{array}{l}\text { Urine specific } \\
\text { gravity }\end{array}$ & $\begin{array}{l}\text { Blood urea } \\
\text { (mg/dL) }\end{array}$ & $\begin{array}{l}\text { Blood glucose } \\
\text { (mg/dL) }\end{array}$ \\
\hline 1 & 152 & & 399 & & & 86 & 110 \\
\hline 2 & 160 & 499 & & 64 & 1.005 & 78 & 109 \\
\hline 3 & 147 & & & & & 82 & 144 \\
\hline 4 & 139 & 490 & 357 & 59 & 1.006 & 81 & 88 \\
\hline 5 & 138 & & & & & 55 & 89 \\
\hline 6 & 139 & & & & & 68 & 101 \\
\hline 7 & 139 & 451 & & 60 & 1.000 & 47 & 129 \\
\hline
\end{tabular}

Sodium imbalance is common after traumatic brain injury. It may develop due to cerebral salt wasting syndrome (CSWS); syndrome of inappropriate antidiuretic hormone secretion (SIADH); central diabetes insipidus (DI); or other causes such as hyperglycemia, administration of mannitol, and hypertonic saline. ${ }^{1}$ However, the combined presentation of DI and CSWS is rarely described and may pose a diagnostic dilemma, affecting management.

A 20-year-old male polytrauma victim with no underlying systemic illness was conservatively managed in the neurointensive care unit for severe head injury. A provisional diagnosis of diffuse axonal injury (DAI) was made based on computed tomography (CT) scan of brain and a gradual improvement of neurological status was observed over days. Three weeks after admission, the patient developed polyuria with hypotension which was managed with crystalloid resuscitation while other possible causes were ruled out. The initial presentation was of hypernatremia with an elevated serum osmolarity ( $339 \mathrm{mOsm} / \mathrm{kg}$ ) which suggested the possibility of central DI. At the same time, the spot sodium level of $64 \mathrm{mEq} / \mathrm{L}$ with hypovolemia and raised blood urea (-Table 1) pointed toward CSWS. The urine specific gravity (1.005) and urine osmolality $(499 \mathrm{~m}$ Osm $/ \mathrm{kg}$ ) were equivocal. Based on the high sodium levels, free water correction was started through enteral route which resulted in gradual reduction in serum $\mathrm{Na}^{+}$levels over the next 48 hours and normalization over the next 7 days. Polyuria persisted for 6 days during which hemodynamic parameters were maintained within normal limits by low-dose noradrenaline infusion, and positive fluid balance was maintained by enteral feeding or intravenous fluids as required. At the end of week, serum sodium level was $139 \mathrm{mEq} / \mathrm{L}$, urine osmolality was $451 \mathrm{mOsm} / \mathrm{kg}$, urine specific gravity was 1.003 , and urine spot sodium was $56 \mathrm{mEq} / \mathrm{L}$ with urea level $47 \mathrm{mg} / \mathrm{dL}$. The patient did not receive any osmotic agents prior to the development of this condition. Serum calcium $(8.8 \mathrm{mg} / \mathrm{dL})$ and daily blood sugar levels were normal (88-144 mg/dL). Renal ultrasonography was unremarkable. Patient became hemodynamically stable and no neurological deterioration was observed.

Our patient did not fit strictly in a picture of central DI as raised urine spot sodium and urine osmolality pointed toward probable concurrent cerebral salt wasting syndrome. The onset of such disturbances have been described between hours to many days after the trauma. ${ }^{2}$ CSWS is reported to occur 2 to 8 days after the onset of central DI. ${ }^{3}$ In our patient, both were noticed almost simultaneously and after 3 weeks of TBI with no known apparent inciting cause for such a delayed presentation. Investigations ruled out other less possible causes like triphasic response of DI-SIADH-DI, partial DI, or nephrogenic DI. Administration of desmopressin for central DI in a case of coexistent CSW, with the aim of suppressing polyuria, might have resulted in severe hyponatremia and, therefore, was avoided. Pharmacotherapy was not administered in our patient and fluid therapy was titrated based on the sodium levels and urine output.

Though less commonly reported, combined CSW and central DI may be an entity going unrecognized. Early suspicion; prompt diagnosis with serum and urine osmolality, and serum and urine sodium levels; along with appropriate treatment can reduce the high morbidity observed in this condition.

\section{Conflict of Interest}

None declared.

\section{References}

1 Mrozek S, Rousset D, Geeraerts T. Pharmacotherapy of sodium disorders in neurocritical care. Curr Opin Crit Care 2019;25(2):132-137

2 Wu X, Zhou X, Gao L, et al. Diagnosis and management of combined central diabetes insipidus and cerebral salt wasting syndrome after traumatic brain injury. World Neurosurg 2016;88:483-487

3 Lin JJ, Lin KL, Hsia SH, Wu CT, Wang HS. Combined central diabetes insipidus and cerebral salt wasting syndrome in children. Pediatr Neurol 2009;40(2):84-87 